\title{
Simultaneous Determination of a Novel Antitrypanosomal Compound (OSU-36) and its Ester Derivative (OSU-40) in Plasma by HPLC: Application to First Pharmacokinetic Study in Rats
}

Pavel Gershkovich $^{\mathrm{a}}$, Kishor M. Wasan ${ }^{\mathrm{a}}$, Olena Sivak ${ }^{\mathrm{a}}$, Summer Lysakowski ${ }^{\mathrm{a}}$, Carolyn Reid ${ }^{\mathrm{b}}$, Kokku Premalatha ${ }^{\mathrm{b}}$, and Karl A. Werbovetz ${ }^{\mathrm{b}}$

${ }^{a}$ Faculty of Pharmaceutical Sciences, University of British Columbia, 2146 East Mall, Vancouver, BC, Canada.

${ }^{b}$ Division of Medicinal Chemistry and Pharmacognosy, College of Pharmacy, The Ohio State University, 500 West $12^{\text {th }}$ Avenue, Columbus, $\mathrm{OH}$, USA.

Received, October 28, 2010; Revised, January 12, 2011; Accepted January 17, 2011; Published January 19, 2011.

ABSTRACT - Purpose. To develop an HPLC-UV method for determination of a novel antitrypanosomal compound (OSU-36) and its ester prodrug (OSU-40) in rat plasma and to apply the method for pharmacokinetic evaluation of both compounds in rats. Methods. Since OSU-36 and OSU-40 were not stable in plasma resulting in highly non-linear calibration curves and poor sensitivity, the plasma samples were stabilized using paraoxon and ascorbic acid. The sample treatment included protein precipitation by acetonitrile; evaporation; reconstitution with acetonitrile and filtration. The chromatography conditions included Xterra RP18 $3.5 \mu \mathrm{m}$ $4.6 \times 100 \mathrm{~mm}$ column and gradient mobile phase system of acetonitrile-water. Results. The limits of quantification (LOQ) using $200 \mu \mathrm{L}$ of plasma sample were $50 \mathrm{ng} / \mathrm{mL}$ and $40 \mathrm{ng} / \mathrm{mL}$ for OSU-36 and OSU-40, respectively. The intra- and interday precision and accuracies were below 13\% for low, medium and high concentration quality control samples for both compounds. While OSU-40 has been stable in all tested handling conditions, OSU-36 was unstable in plasma after 20 days storage at $-80^{\circ} \mathrm{C}$ or at $4 \mathrm{~h} 25^{\circ} \mathrm{C}$ storage. The developed method has been applied for a pharmacokinetic study in rats which revealed that an ester prodrug OSU-40 is rapidly converted to OSU-36 within the plasma compartment by plasma esterases. OSU-36, in turn, relatively quickly undergoes oxidative metabolism, including within the plasma compartment. Conclusions. A supplementation of rat plasma with an esterase inhibitor to prevent degradation of ester prodrug (OSU-40), and with antioxidant to prevent oxidation of OSU-36, is necessary for reliable determination of both compounds. Due to limited stability of OSU-36 even in stabilized rat plasma, long-term storage of samples or prolonged handling in room temperature conditions is not recommended.

\section{INTRODUCTION}

Human African trypanosomiasis (HAT) or sleeping sickness is a devastating disease caused by extracellular protozoan Trypanosoma brucei subspecies. The parasites are transmitted by the bite of infected tsetse flies which are exclusively found in subSaharan Africa. The disease has two stages, at the first stage the parasites reside in the blood and lymph systems, while at the second stage the parasites penetrate into central nervous system. Human African trypanosomiasis (HAT) is fatal if left untreated (1-3). It is estimated that there are up to 70000 cases that actually occur annually (including unreported cases) with about 60 million people at risk of infection (3-5). The World Health Organization (WHO) estimated that only about $10 \%$ of new cases are actually diagnosed $(4,5)$.
The treatment options for HAT are highly limited. Pentamidine or suramin are used to treat the infection at the first phase only, since these compounds do not penetrate the blood-brain barrier. Melarsoprol is the most common drug for the second phase of the disease, but it is associated with $10 \%$ incidence of a fatal encephalopathy. Eflornithine is a newer and safer alternative for melarsoprol in the case of infection by Trypanosoma brucei gambiense only, but it requires long-term intravenous treatment which practically makes this treatment unaffordable and inaccessible by those in need.

\footnotetext{
Corresponding author: Pavel Gershkovich, $\mathrm{PhD}$; Division of Pharmaceutics and Biopharmaceutics, Faculty of Pharmaceutical Sciences The University of British Columbia, Vancouver, British Columbia, Canada; Email:pgershko@interchange.ubc.ca
} 
Parasite resistance-associated treatment failures are reported for both melarsoprol (as high as 30\%) and eflornithine (1). There is a desperate need for safer and affordable treatment options for the second stage of sleeping sickness $(1,6)$.

Recently, a series of novel dihydroquinolines has been evaluated in vitro and in vivo in mice for antitrypanosomal activity as well as cytotoxicity. OSU-36 (1 - Benzy 1 - 1, 2- dihydro - 2, 2, 4 trimethylquinolin-6-ol or compound 9a in Ref. 1) and especially its ester pro-drug OSU-40 (1-Benzyl1,2-dihydro-2,2,4-trimethylquinolin-6-yl acetate or compound 10a in the referenced study) (Fig. 1) were found to be promising antitrypanosomal compounds in regard to their activity/toxicity index (1).

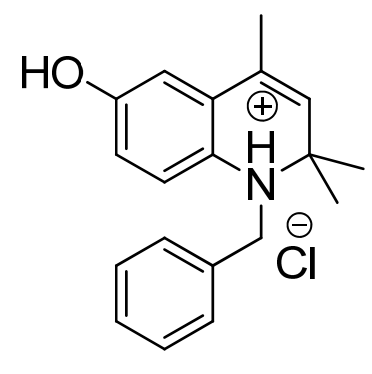

A

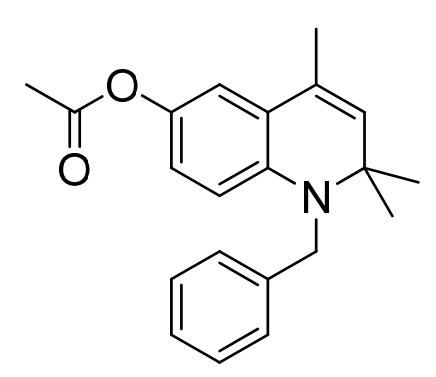

B
Figure 1. Chemical structures of OSU-36 hydrochloride (A) and OSU-40 (B).

It was hypothesized that the mechanism of action of these novel 1,2- dihydroquinolines is related to an increase of oxidative stress on the parasite to form a quinone imine intermediate from OSU-36 in the in vivo system. The quinone imine can undergo a single electron reduction to form a semiquinone which may enhance the rate of formation of reactive oxygen species (1).

The analysis of OSU-40 and of OSU-36 represented a significant challenge due to the fact that OSU-40 is an unstable ester prodrug which is rapidly converted to OSU-36 in the blood compartment by plasma esterases, and this process is continued after sample collection. OSU-36 is, in turn, quickly oxidized in the blood compartment and this process is also continued in the vials after sample collection. An attempt to assay OSU-36 and OSU-40 in non-stabilized plasma resulted in highly non-linear calibration curves and poor sensitivity. A supplementation of rat plasma with an esterase inhibitor (paraoxon) to prevent degradation of ester prodrug (OSU-40), and with an antioxidant (ascorbic acid) to prevent oxidation of OSU-36 was necessary for reliable determination of both compounds.

The aim of the current study was to develop an analytical method for determination of OSU-36 and its ester derivative, OSU-40 in plasma and to assess the pharmacokinetics of these compounds following intravenous administration in rats.

\section{METHODS}

\section{Chemicals and reagents}

The synthesis and purification of OSU-40 (1benzyl-1,2-dihydro-2,2,4-trimethylquinolin-6-yl acetate) has been previously reported by the authors (compound 10a in the referenced work) (1). The hydrochloride salt of OSU-36 (1-benzyl-1,2dihydro-2,2,4-trimethylquinolin-6-ol hydrochloride), which is stable when stored as a solid, was prepared as described by Reid et al. (7). Probucol, L-Ascorbic acid and polyethylene glycol 400 were purchased from Sigma-Aldrich (St. Louis, MO, USA) and used as received. HPLC grade acetonitrile, methanol and water were purchased from Fisher Scientific (Fair Lawn, NJ, USA).

\section{Preparation of standard solutions and quality control samples}

Stock standard solutions of the analytes (OSU-40 and OSU-36) and the internal standard (IS) (probucol) were prepared in acetonitrile at a concentration of $1 \mathrm{mg} \mathrm{mL} \mathrm{m}^{-1}$ and stored at $-20^{\circ} \mathrm{C}$. Working standard solutions of the analytes (50 $\mu \mathrm{g} / \mathrm{mL})$ and of the IS $(20 \mu \mathrm{g} / \mathrm{mL})$ were prepared by dilutions of stock solutions in acetonitrile and stored at $-20^{\circ} \mathrm{C}$. The solutions of the analytes and of IS were stable for at least 3 months under the described conditions.

The working solutions of analytes were diluted by acetonitrile immediately before preparation of calibration curves to obtain stock concentrations of 50000, 25000, 12500, 6250, 3125, 1563 and 781 $\mathrm{ng} / \mathrm{mL}$. The plasma calibration curves were prepared at concentrations of $2500,1250,625,312$, $156,78,39$ and $0 \mathrm{ng} / \mathrm{mL}$ by spiking $180 \mu \mathrm{L}$ of stabilized plasma (see sample preparation section) with $10 \mu \mathrm{L}$ of working standard of each analyte at appropriate concentration (to make up to $200 \mu \mathrm{L}$ 
total sample volume). To each sample was added $10 \mu \mathrm{L}$ of IS $(20 \mu \mathrm{g} / \mathrm{mL})$ and the samples were vortexed for $5 \mathrm{sec}$.

The independently prepared stock solutions of OSU-36 hydrochloride in acetonitrile in concentrations of $1.0 \mu \mathrm{g} / \mathrm{mL}, 2 \mu \mathrm{g} / \mathrm{mL}, 20 \mu \mathrm{g} / \mathrm{mL}$ and $50 \mu \mathrm{g} / \mathrm{mL}$, of OSU-40 in acetonitrile in concentrations of $0.8 \mu \mathrm{g} / \mathrm{mL}, 2 \mu \mathrm{g} / \mathrm{mL}, 20 \mu \mathrm{g} / \mathrm{mL}$ and $50 \mu \mathrm{g} / \mathrm{mL}$ and of IS in a concentration of 20 $\mu \mathrm{g} / \mathrm{mL}$ were used for preparation of QC (quality control) samples. The QC samples were independently prepared in stabilized plasma at four levels of concentrations for OSU-36: $50 \mathrm{ng} / \mathrm{mL}$ (limit of quantification (LOQ)), $100 \mathrm{ng} / \mathrm{mL}$ (low concentration quality control (LQC)), $1000 \mathrm{ng} / \mathrm{mL}$ (medium concentration quality control (MQC)) and $2500 \mathrm{ng} / \mathrm{mL}$ (high concentration quality control (HQC)) and for OSU-40: $40 \mathrm{ng} / \mathrm{mL}$ (LOQ), 100 $\mathrm{ng} / \mathrm{mL}$ (LQC), $1000 \mathrm{ng} / \mathrm{mL}$ (MQC) and 2500 $\mathrm{ng} / \mathrm{mL}$ (HQC).

\section{Sample preparation}

The plasma samples were stabilized by addition of $10^{-4} \mathrm{M}$ of paraoxon and $1.7 \times 10^{-3} \mathrm{M}$ of L-ascorbic acid. In the pharmacokinetic study, appropriate amounts of paraoxon and L-ascorbic acid solution were added to empty microcentrifuge tubes before the blood collection to create identical concentrations of paraoxon and L-ascorbic acid. 10 $\mu \mathrm{L}$ of IS solution $(20 \mu \mathrm{g} / \mathrm{mL})$ were added to $200 \mu \mathrm{L}$ of plasma samples and proteins were precipitated by addition of $400 \mu \mathrm{L}$ of cold $\left(4^{\circ} \mathrm{C}\right)$ acetonitrile, vortex-mixing for $1 \mathrm{~min}$ and centrifugation at $10,000 \mathrm{rpm}$ for $10 \mathrm{~min}$ at $4{ }^{\circ} \mathrm{C} .500 \mu \mathrm{L}$ of the supernatant were transferred to a fresh tube and evaporated to dryness under nitrogen. The samples were then reconstituted with $90 \mu \mathrm{L}$ of acetonitrile, vortex-mixed for $1 \mathrm{~min}$, filtered using Ultrafree ${ }^{\circledR}$ Durapore PVDF $0.22 \mu \mathrm{m}$ centirifugal filters (Millipore Corporation, Billerica, MA, USA) at $10,000 \mathrm{rpm}, 4{ }^{\circ} \mathrm{C}$ for $3 \mathrm{~min}$, and transferred to HPLC vials.

\section{Instrumentation and analytical conditions}

Analysis was performed using a Waters 2695 Separation Module HPLC system with Waters 996 Photodiode Array Detector (Waters Corporation, Milford, MA, USA). Aliquots of $30 \mu \mathrm{L}$ were injected into the HPLC system. Chromatographic separations were performed using Xterra RP18 $3.5 \mu \mathrm{m} 4.6 \mathrm{X} 100 \mathrm{~mm}$ column maintained at $45^{\circ} \mathrm{C}$.
The flow rate was set at $0.6 \mathrm{~mL} / \mathrm{min}$ and mobile phase composition was gradient with the following elution program: from acetonitrile-water (50:50, $\mathrm{v} / \mathrm{v})$ to acetonitrile-water $(96: 4, \mathrm{v} / \mathrm{v})$ in $15 \mathrm{~min}$; then $5 \mathrm{~min}$ at acetonitrile-water $(96: 4, \mathrm{v} / \mathrm{v})$ isocratic; then to acetonitrile-water $(50: 50, \mathrm{v} / \mathrm{v})$ in $5 \mathrm{~min}$; then further $5 \mathrm{~min}$ at acetonitrile-water $(50: 50, \mathrm{v} / \mathrm{v})$. OSU-36, OSU-40 and IS were eluted at 8.8, 10.5 and $18.1 \mathrm{~min}$ and detected at the wavelengths of 370,358 and $260 \mathrm{~nm}$, respectively.

\section{Method validation}

\section{Selectivity}

Selectivity of the method was investigated by comparing chromatograms of extracted blank plasma obtained from 12 different rats with those of standard plasma samples spiked with OSU-36, OSU-40 and IS, as well as with those obtained after intravenous administrations of OSU-36 and OSU40.

\section{Intra-day and inter-day precision and accuracy}

The intra-day precision (expressed as relative standard deviation (RSD)) and accuracy (expressed as relative error (RE)) was determined within one day by analyzing six replicates of samples at concentrations of 50 (LOQ), 100 (LQC), 1000 (MQC) and $2500 \mathrm{ng} / \mathrm{mL}$ (HQC) for OSU-36, and at concentrations of 40 (LOQ), 100 (LQC), 1000 (MQC) and $2500 \mathrm{ng} / \mathrm{mL}$ (HQC) for OSU-40. The inter-day precision and accuracy was determined at 6 separate days (over a period of one month) at identical concentrations.

\section{Sensitivity}

The limit of quantification (LOQ) for both compounds was defined as the lowest concentration of spiked plasma that can be determined with sufficient precision and accuracy (i.e., RSD $<20 \%$ and $-20 \%<\mathrm{RE}<20 \%$ ) for both intra-day and interday runs (8).

\section{Recovery}

To quantify for the loss of the compounds during the sample treatment process, the recovery of the method was determined as the ratio of the peak area of extracted QC samples after a full assay process to that from direct injection of equivalent concentrations of compounds in acetonitrile. The recovery of IS was determined in a similar way. 


\section{Stability}

The storage stability was evaluated by determining LQC, MQC and HQC plasma samples at different conditions ( $\mathrm{n}=6$ for each level and for each tested condition): following storage for 20 days at $-80^{\circ} \mathrm{C}$ (long-term stability); following storage for 24 hours at $-80^{\circ} \mathrm{C}$ (short-term stability), following storage for 4 hours at $25^{\circ} \mathrm{C}$ (room temperature stability); and following 16 hours storage of samples ready for injection into HPLC system in autosampler at $4{ }^{\circ} \mathrm{C}$ (autosampler stability).

\section{Pharmacokinetic study}

The animal protocols used in this study were approved by the University of British Columbia's Animal Care Committee and conform to the Canadian Council on Animal Care guidelines. Male Sprague Dawley rats (UBC animal care center, Vancouver, BC, Canada) weighing 330-350 g were used in this study. The rats were kept under a 12-h light/dark cycle with free access to water and food (regular rat chow).

The right external jugular vein was cannulated with a two-part catheter consisting from PE-50 connected to silastic tubing. Twenty four hours following surgery animals were allocated into 2 treatment groups: intravenous bolus (via jugular vein cannula) of OSU-40 $2 \mathrm{mg} / \mathrm{mL}$ solution in a mixture of PEG-400: ethanol: sterile water $(70: 10: 20, \mathrm{v} / \mathrm{v} / \mathrm{v})$ in the dose of $2 \mathrm{mg} / \mathrm{kg}(\mathrm{n}=6)$; and intravenous bolus of OSU-36 solubilized in the same formulation $(2 \mathrm{mg} / \mathrm{mL})$ in the dose of $2 \mathrm{mg} / \mathrm{kg}$ $(\mathrm{n}=6)$. Systemic blood $(0.2 \mathrm{~mL})$ was sampled from jugular vein cannula before the dosing and $0.45 \mathrm{~mL}$ of blood was sampled at 2, 5, 10, 15, 20, 30, 60, 120 and 240 min following administration of both compounds. Plasma was separated by centrifugation $\left(5000 \mathrm{rpm}, 10 \mathrm{~min}, 15^{\circ} \mathrm{C}\right.$ ) and stored at $-80^{\circ} \mathrm{C}$ until analysis (not more than 24 hours). WinNonlin 5.0.1 Professional was used for pharmacokinetic analysis of the data by non-compartmental approach.

\section{RESULTS}

\section{Method validation}

\section{Selectivity}

Fig. 2 shows the chromatograms that represent blank plasma at $370 \mathrm{~nm}$ (panel A), plasma spiked with OSU-36 and OSU-40 at $370 \mathrm{~nm}$ detection wavelength (panel B) and plasma spiked with both compounds plus IS (probucol) at $260 \mathrm{~nm}$ (panel C). The proposed assay was found to be highly selective since there were no interferences by endogenous plasma peaks with the compounds of interest at the detection wavelengths (i.e., $370 \mathrm{~nm}$, $358 \mathrm{~nm}$ and $260 \mathrm{~nm}$ for OSU-36, OSU-40 and probucol, respectively).

\section{Sensitivity and linearity}

The limit of quantification (LOQ) for both compounds (i.e., the lowest concentration of spiked plasma that can be determined with RSD $<20 \%$ and $-20 \%<\mathrm{RE}<20 \%$ for both intra-day and interday runs) is shown in Table 1 and is found to be 40 $\mathrm{ng} / \mathrm{mL}$ for OSU-40 and $50 \mathrm{ng} / \mathrm{mL}$ for OSU-36 (8). The linearity of the developed assay was confirmed for the range of LOQ $-2500 \mathrm{ng} / \mathrm{mL}$ for both compounds (based on 8 concentration levels), with an $\mathrm{r}^{2}$ above 0.99 .

\section{Intra-day and inter-day precision and accuracy}

The intra-day and inter-day precision (expressed as RSD\%) and accuracy (expressed as RE\%) for OSU40 and OSU-36 are shown in Table 1. Both intraand inter-day precisions and accuracies are within acceptable limits (i.e., less than $15 \%$ for $\mathrm{RSD} \%$ and $\mathrm{RE} \%$ ) for low $\mathrm{QC}$, medium $\mathrm{QC}$ and high $\mathrm{QC}$ samples (8).

\section{Recovery}

The absolute recovery of OSU-40 following all the assay steps was $56.2 \pm 4.6 \%, 70.0 \pm 6.3 \%$, and 75.0 $\pm 3.5 \%$ for LQC, MQC and HQC samples, respectively. The absolute recovery of OSU-36 was $76.0 \pm 25.1 \%, 82.4 \pm 8.9 \%$, and $89.5 \pm 4.0 \%$ for LQC, MQC and HQC samples, respectively. The absolute recovery of the IS at the concentration used in this method was $58.7 \pm 4.0 \%$.

\section{Stability}

The stability of OSU-40 and OSU-36 at LQC, MQC and HQC levels under different handling and storage conditions is presented in Table 2. OSU-40 was stable in all tested conditions, including longterm (20 days) storage of plasma samples at $-80^{\circ} \mathrm{C}$ or prolonged (4 hours) handling in room temperature. On the other hand, OSU-36 showed limited stability when stored for 20 days at $-80^{\circ} \mathrm{C}$ or when the plasma samples were left at room temperature for 4 hours. 

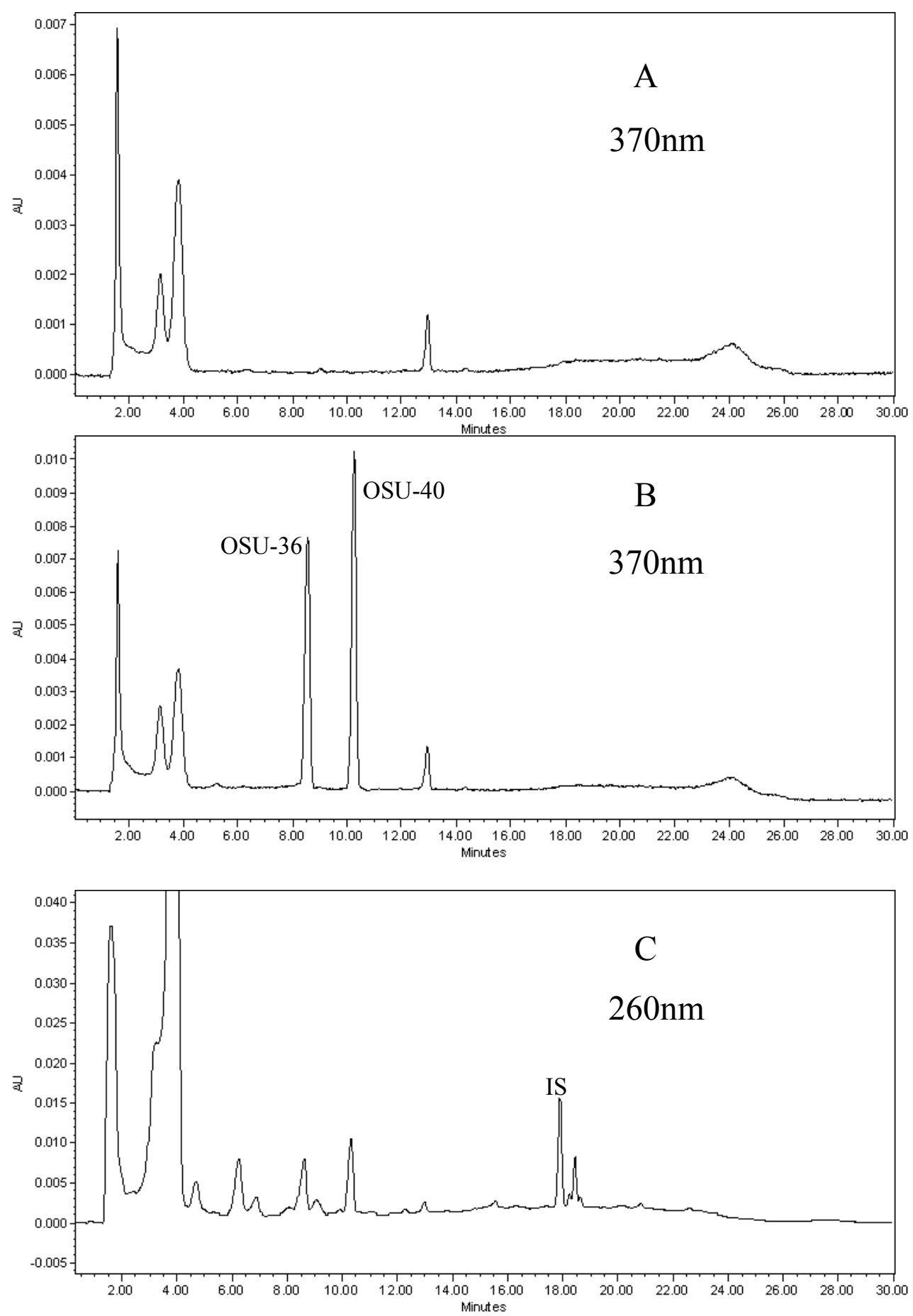

Figure 2. Representative chromatography of blank plasma sample detected at $370 \mathrm{~nm}(\mathrm{~A})$, plasma spiked with OSU-36 and OSU-40 detected at $370 \mathrm{~nm}$ (B) and plasma sample spiked with OSU-36, OSU-40 and probucol (IS) detected at 260nm (C). 
Table 1. Intra-day and inter-day precision and accuracy data for the determination of OSU-40 and OSU-36 in rat plasma

\begin{tabular}{|c|c|c|c|c|}
\hline \multirow{3}{*}{ Level } & \multicolumn{4}{|c|}{ OSU-40 } \\
\hline & \multicolumn{2}{|c|}{ Intra-day $(n=6)$} & \multicolumn{2}{|c|}{ Inter-day $(n=6)$} \\
\hline & RSD \% & RE \% & RSD \% & RE \% \\
\hline LLOQ (40 ng/mL) & 6.5 & 18.8 & 14.7 & 9.2 \\
\hline LQC (100 ng/mL) & 10.6 & 12.1 & 11.2 & -4.6 \\
\hline MQC (1000 ng/mL) & 6.8 & 2.4 & 9.4 & 6.3 \\
\hline HQC (2500 ng/mL) & 1.7 & 7.3 & 8.9 & 2.6 \\
\hline
\end{tabular}

\begin{tabular}{|c|c|c|c|c|}
\hline \multirow{3}{*}{ Level } & \multicolumn{4}{|c|}{ OSU-36 } \\
\hline & \multicolumn{2}{|c|}{ Intra-day $(n=6)$} & \multicolumn{2}{|c|}{ Inter-day $(n=6)$} \\
\hline & RSD \% & RE \% & RSD \% & RE \% \\
\hline LLOQ (50 ng/mL) & 6.9 & 3.3 & 13.6 & -5.3 \\
\hline LQC (100 ng/mL) & 7.4 & -3.4 & 9.9 & -7.2 \\
\hline MQC (1000 ng/mL) & 8.4 & -10.7 & 14.9 & -2.8 \\
\hline HQC (2500 ng/mL) & 7.2 & -2.2 & 13.0 & -6.0 \\
\hline
\end{tabular}

\begin{tabular}{|c|c|c|c|c|c|c|c|c|}
\hline \multirow{3}{*}{ Level } & \multicolumn{8}{|c|}{ OSU-40 } \\
\hline & \multicolumn{2}{|c|}{$\begin{array}{c}\text { Long-term } \\
\left(-80^{\circ} \mathrm{C}, 20 \text { days }\right)\end{array}$} & \multicolumn{2}{|c|}{$\begin{array}{l}\text { Short-term } \\
\left(-80^{\circ} \mathrm{C}, 24 \mathrm{~h}\right)\end{array}$} & \multicolumn{2}{|c|}{$\begin{array}{l}\text { Room temp. } \\
\left(25^{\circ} \mathrm{C}, 4 \mathrm{~h}\right)\end{array}$} & \multicolumn{2}{|c|}{$\begin{array}{c}\text { Autosampler } \\
\left(-4^{\circ} \mathrm{C}, 16 \mathrm{~h}\right)\end{array}$} \\
\hline & RSD \% & RE \% & RSD \% & RE \% & RSD \% & RE \% & RS \% & RE \% \\
\hline LQC (100 ng/mL) & 1.9 & 4.4 & 8.2 & 9.3 & 13.6 & 4.7 & 8.5 & 7.9 \\
\hline MQC (1000 ng/mL) & 5.2 & -8.4 & 4.1 & 13.4 & 4.7 & -9.5 & 4.2 & -3.7 \\
\hline HQC $(2500 \mathrm{ng} / \mathrm{mL})$ & 7.2 & -9.9 & 3.8 & 11.8 & 5.6 & -6.3 & 4.7 & -7.5 \\
\hline \multirow[t]{2}{*}{ Level } & \multicolumn{2}{|c|}{$\begin{array}{c}\text { Long-term } \\
\left(-80^{\circ} \mathrm{C}, 20 \text { days }\right)\end{array}$} & \multicolumn{2}{|c|}{$\begin{array}{l}\text { Short-term } \\
\left(-80^{\circ} \mathrm{C}, 24 \mathrm{~h}\right)\end{array}$} & \multicolumn{2}{|c|}{$\begin{array}{l}\text { Room temp. } \\
\left(25^{\circ} \mathrm{C}, 4 \mathrm{~h}\right)\end{array}$} & \multicolumn{2}{|c|}{$\begin{array}{c}\text { Autosampler } \\
\left(-4^{\circ} \mathrm{C}, 16 \mathrm{~h}\right)\end{array}$} \\
\hline & RSD \% & RE \% & RSD \% & RE \% & RSD \% & RE \% & RSD \% & RE \% \\
\hline LQC (100 ng/mL) & 8.4 & -17.1 & 12.1 & 8.3 & 9.5 & -9.4 & 12.5 & -4.3 \\
\hline MQC $(1000 \mathrm{ng} / \mathrm{mL})$ & 2.9 & -25.0 & 1.3 & 13.0 & 9.7 & -11.4 & 3.6 & -14.0 \\
\hline HQC $(2500 \mathrm{ng} / \mathrm{mL})$ & 12.9 & -33.7 & 1.2 & 9.8 & 12.5 & -19.5 & 5.3 & -11.2 \\
\hline
\end{tabular}

Both compounds showed acceptable stability for short-term (24 hours) storage at $-80^{\circ} \mathrm{C}$ and autosampler stability of processed samples $\left(4^{\circ} \mathrm{C}, 16\right.$ hours) (RSD and RE within 15\% at all QC levels).

\section{Pharmacokinetic study}

The developed method was applied to a first pharmacokinetic study of OSU-36 and OSU-40 in rats. The plasma concentration-time profile of OSU-36 following IV bolus administration of $2 \mathrm{mg} / \mathrm{kg}$ of OSU-36 hydrochloride, as well as plasma concentration-time profiles of OSU-36 and OSU-40 following IV bolus administration of 2 $\mathrm{mg} / \mathrm{kg}$ of OSU-40 are shown in Figure 3. The pharmacokinetic parameters derived from plasma concentration-time profiles of OSU-36 and OSU-40 are summarized in Table 3. The IV bolus administration of OSU-40 resulted in rapid clearance of the parent compound with elimination half-life of less than $5 \mathrm{~min}$. Consistently, following the administration of OSU-40 the plasma concentrations of OSU-36 were at the maximal measured level at the first sample time point (2 $\mathrm{min})$. The half-life of OSU-36 was around $40 \mathrm{~min}$ following both IV bolus of OSU-36 and OSU-40. Data are summarized in Table 3. 


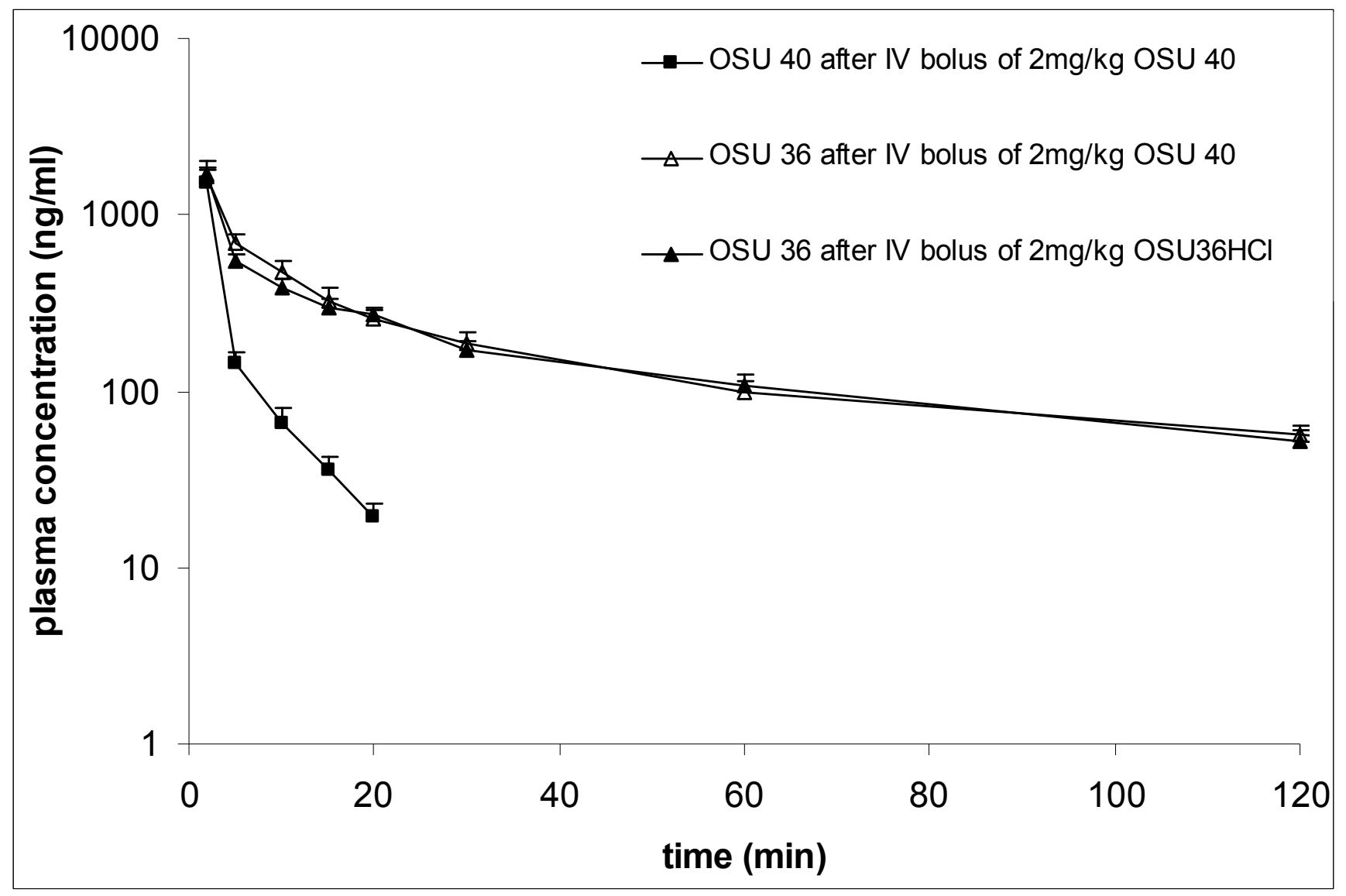

Figure 3. The plasma concentration-time profile (mean \pm SEM) of OSU-36 following IV bolus administration of $2 \mathrm{mg} / \mathrm{kg}$ of OSU-36 hydrochloride and plasma concentration-time profiles of OSU-36 and OSU-40 following IV bolus administration of $2 \mathrm{mg} / \mathrm{kg}$ of OSU-40.

Table 3. Pharmacokinetic parameters derived from plasma concentration-time profiles of OSU-36 and OSU-40 following IV bolus administration of OSU-40 or OSU-36 (mean \pm SEM).

\begin{tabular}{ccccc}
\hline & $\begin{array}{c}\mathbf{A U C} \text { inf } \\
\text { (min*ng/mL) }\end{array}$ & $\begin{array}{c}\text { Vd } \\
\text { (mL/kg) }\end{array}$ & $\begin{array}{c}\text { Cl } \\
\text { (mL/min/kg) }\end{array}$ & $\begin{array}{c}\mathbf{T}_{\mathbf{1} / \mathbf{2}} \\
(\mathbf{m i n})\end{array}$ \\
\hline $\begin{array}{c}\text { OSU-40 following IV bolus of } \\
\mathbf{2} \mathbf{m g} / \mathbf{k g} \text { of OSU-40 }\end{array}$ & $14626 \pm 5008$ & $1450 \pm 309$ & $239 \pm 75$ & $4.8 \pm 0.4$ \\
$\begin{array}{c}\text { OSU-36 following IV bolus of } \\
\mathbf{2} \mathbf{m g} / \mathbf{k g} \text { of OSU-40 }\end{array}$ & $24767 \pm 3351$ & - & - & $41.9 \pm 4.7$ \\
$\begin{array}{c}\text { OSU-36 following IV bolus of } \\
\mathbf{2 m g / k g} \text { of OSU-36 }\end{array}$ & $29195 \pm 2782$ & $3881 \pm 453$ & $63 \pm 6$ & $43.9 \pm 5.9$ \\
\hline
\end{tabular}

\section{DISCUSSION}

The stability of both OSU-40 and OSU-36 in plasma samples presented the most significant challenge in the analytical method development.
OSU-40 is an ester prodrug and is quickly converted to OSU-36 by plasma esterases. This process is continued after sample collection in the test tube and thus must be inhibited for reliable determination of OSU-40 in plasma samples. 
Spiking of non-stabilized plasma samples with OSU-40 resulted in an appearance of both OSU-40 and OSU-36 peaks on the chromatogram even when the samples were assayed immediately following the spiking (Fig. 4 A). Thus, the plasma has been stabilized by an esterase inhibitor paraoxon at a concentration of $10^{-4} \mathrm{M}$. Paraoxon is a potent esterase inhibitor which binds irreversibly to the serine residue at the active site of esterases and has been shown to inhibit almost completely hydrolysis of ester prodrugs in plasma at a concentration as low as $10^{-6} \mathrm{M}(9-11)$. The spiking of the stabilized plasma by OSU-40 resulted in a single peak of OSU-40 without OSU-36 contamination (Fig 4 B).

The development of the assay was further complicated by the instability of OSU-36 in the plasma samples. OSU-36 undergoes rapid oxidation in plasma samples and this process occured, as well, in blood and plasma samples after the sampling. An attempt to assay for OSU-36 in unstabilized plasma resulted in poor sensitivity and highly non-linear calibration curves. Therefore, the plasma was stabilized by ascorbic acid, which is a potent antioxidant that has previously been shown to prevent oxidative degradation of a number of compounds in plasma $(12,13)$. Although a concentration of $0.1 \mathrm{mg} / \mathrm{ml}\left(5.7 \times 10^{-4} \mathrm{M}\right)$ has been found to be effective in previous work with rifampin (13), a 3-fold higher concentration $(0.3$ $\mathrm{mg} / \mathrm{ml}$, or $1.7 \times 10^{-3} \mathrm{M}$ ) of ascorbic acid was found to be optimal for prevention of oxidative degradation of OSU-36 in our hands.
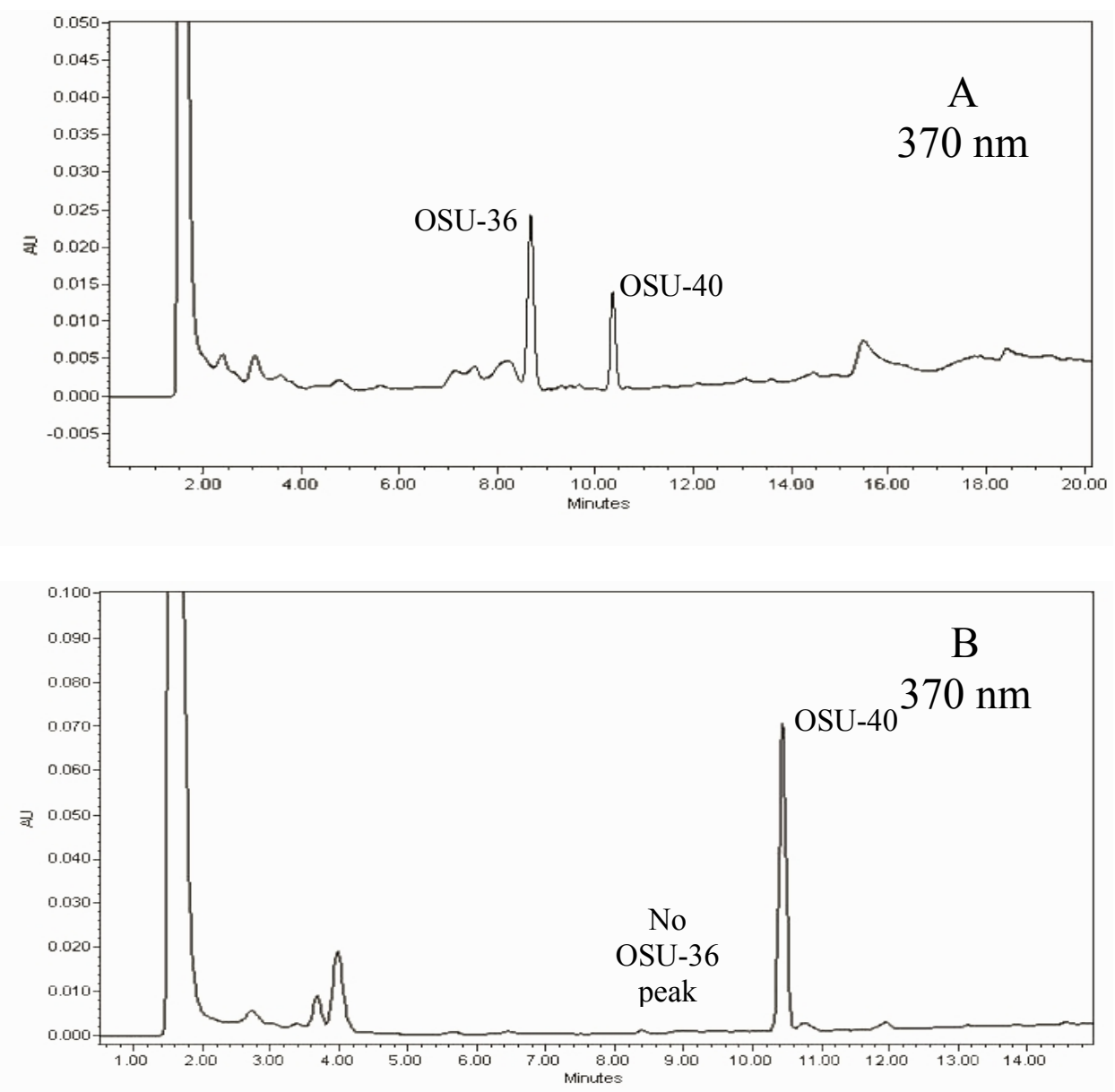

Figure 4. Chromatograms at initial stages of analytical method development detected at $370 \mathrm{~nm}$. Panel A shows a chromatogram of non-stabilized plasma spiked with OSU-40 (peaks of both OSU-40 and OSU-36 appears on the chromatogram). Panel B shows a chromatogram of plasma stabilized with paraoxon and spiked with OSU-40 (only peak of OSU-40 can be seen on the chromatogram). 
Further escalation of the concentration of ascorbic acid has not provided stability improvement. The addition of ascorbic acid and paraoxon to the samples resulted in acceptable sensitivity and in linear calibration curves for both OSU-40 and OSU-36 in the range of LOQ - $2500 \mathrm{ng} / \mathrm{mL}$. Once the plasma samples were stabilized, the further sample treatment process was simple and included protein precipitation by cold acetonitrile, concentration of the samples by evaporation and reconstitution in reduced volume of acetonitrile, and filtration.

The chromatography conditions included a buffer-free acetonitrile-water based gradient mobile phase. The buffer-free conditions can simplify the transfer of the method to LC-MS conditions, if needed. The Xterra RP18 $3.5 \mu \mathrm{m} 4.6$ X100 mm column maintained at $45^{\circ} \mathrm{C}$ (to improve separation efficiency) provided a good separation of the compounds. However, for both OSU-36 and OSU40 the optimal detection wavelengths were found to be not at the absolute maximum of $230 \mathrm{~nm}$ but at a secondary maximum of $370 \mathrm{~nm}$ (for OSU-36) or at $358 \mathrm{~nm}$ (for OSU-40), due to contaminants observed in the plasma samples at $230 \mathrm{~nm}$.

The intra- and inter-day precisions and accuracies below $15 \%$ indicate that in stabilized rat plasma samples concentrations of both OSU-40 and OSU-36 can be determined with reasonable precision and accuracy and these methods can be used for pharmacokinetic studies.

The stability data confirms that the method is suitable for preclinical pharmacokinetic experiments. However, for reliable determination of OSU-36 plasma samples should not be stored for a longer than 24 hours and should be assayed immediately after thawing.

Both the quick disappearance of OSU-40 from the plasma (half-life below $5 \mathrm{~min}$ ) and the rapid formation of OSU-36 (maximal concentration at first measured time point of $2 \mathrm{~min}$ after administration of OSU-40) suggest rapid conversion of OSU-40 into OSU-36 by plasma esterases within the central (blood) compartment. The IV bolus administration of OSU-36 hydrochloride resulted in dose corrected AUC practically identical to the one obtained following administration of OSU-40. This suggests complete or near to complete conversion of OSU-40 to OSU36 once the parent compound reaches the systemic circulation. The lower apparent volume of distribution of OSU-40 (despite its higher lipophilicity) also suggests that OSU-40 is quickly converted to OSU-36 in central compartment before it can be efficiently distributed into body tissues.

In conclusion, development of the analytical method for determination of OSU-40 and OSU-36 in plasma presented a significant challenge mostly due to instability of both compounds in plasma samples. Supplementation of rat plasma with an esterase inhibitor (paraoxon) to prevent degradation of ester prodrug (OSU-40), and with an antioxidant (ascorbic acid) to prevent oxidation of OSU-36 was necessary for reliable determination of both compounds. The developed method was successfully applied for a pharmacokinetic study of both compounds in rats and first pharmacokinetic parameters were obtained for these promising novel molecules with antitrypanosomal activity. However, for reliable determination of OSU-36 plasma samples should not be stored for a long time following the experiment and should be assayed immediately after thawing.

\section{ACKNOWLEDGMENTS}

This work was supported by Canadian Institutes of Health Research (CIHR) and Neglected Global Diseases Initiative of University of British Columbia (NGDI-UBC).

\section{REFERENCES}

1. Fotie J, Kaiser M, Delfin DA, Manley J, Reid CS, Paris JM, et al. Antitrypanosomal activity of 1,2dihydroquinolin-6-ols and their ester derivatives. J Med Chem 2010;53(3):966-82.

2. Steverding D. The development of drugs for treatment of sleeping sickness: a historical review. Parasit Vectors 2010;3(1):15.

3. Fevre EM, Wissmann BV, Welburn SC, Lutumba P. The burden of human African trypanosomiasis. PLoS Negl Trop Dis 2008;2(12):e333.

4. Rodgers J. Human African trypanosomiasis, chemotherapy and CNS disease. J Neuroimmunol 2009;211(1-2):16-22.

5. WHO. Human African trypanosomiasis (sleeping sickness): epidemiological update. Wkly. Epidemiol. Rec. 2006;81:71-80.

6. Welburn SC, Maudlin I, Simarro PP. Controlling sleeping sickness - a review. Parasitology 2009;136(14):1943-9.

7. Reid CS, Patrick DA, He S, Fotie J, Premalatha K, Tidwell RR, et al. Synthesis and antitrypanosomal 
evaluation of derivatives of N-benzyl-1,2dihydroquinolin-6-ols: Effect of core substitutions and salt formation. Bioorg Med Chem 2011;19(1):513-23.

8. Karnes HT, March C. Precision, accuracy, and data acceptance criteria in biopharmaceutical analysis. Pharm Res 1993;10(10):1420-6.

9. Liederer BM, Borchardt RT. Stability of oxymethylmodified coumarinic acid cyclic prodrugs of diastereomeric opioid peptides in biological media from various animal species including human. J Pharm Sci 2005;94(10):2198-206.

10. Yoshigae $\mathrm{Y}$, Imai $\mathrm{T}$, Taketani $\mathrm{M}$, Otagiri $\mathrm{M}$. Characterization of esterases involved in the stereoselective hydrolysis of ester-type prodrugs of propranolol in rat liver and plasma. Chirality 1999;11(1):10-3.
11. Zeng J, Onthank D, Crane P, Unger S, Zheng N, Pasas-Farmer S, et al. Simultaneous determination of a selective adenosine 2A agonist, BMS-068645, and its acid metabolite in human plasma by liquid chromatography-tandem mass spectrometry-evaluation of the esterase inhibitor, diisopropyl fluorophosphate, in the stabilization of a labile estercontaining drug. J Chromatogr B Analyt Technol Biomed Life Sci 2007;852(1-2):77-84.

12. Hugh D, Grennan A, Abugila MA, Weinkove C. Ascorbic acid as an antioxidant in measurements of catecholamines in plasma. Clin Chem 1987;33(4):569-71.

13. Le Guellec C, Gaudet ML, Lamanetre S, Breteau M. Stability of rifampin in plasma: consequences for therapeutic monitoring and pharmacokinetic studies. Ther Drug Monit 1997;19(6):669-74. 